\title{
Graphene Liquid Enclosure for Single-Molecule Analysis of Membrane Proteins in Whole Cells Using Electron Microscopy
}

DOI:

10.1021/acsnano.7b05258

\section{Document Version}

Accepted author manuscript

Link to publication record in Manchester Research Explorer

Citation for published version (APA):

Dahmke, I. N., Verch, A., Hermannsdoerfer, J., Peckys, D. B., Weatherup, R. S., Hofmann, S., \& de Jonge, N. (2017). Graphene Liquid Enclosure for Single-Molecule Analysis of Membrane Proteins in Whole Cells Using Electron Microscopy. ACS Nano, 11, 11108-11117. https://doi.org/10.1021/acsnano.7b05258

\section{Published in:}

ACS Nano

\section{Citing this paper}

Please note that where the full-text provided on Manchester Research Explorer is the Author Accepted Manuscript or Proof version this may differ from the final Published version. If citing, it is advised that you check and use the publisher's definitive version.

\section{General rights}

Copyright and moral rights for the publications made accessible in the Research Explorer are retained by the authors and/or other copyright owners and it is a condition of accessing publications that users recognise and abide by the legal requirements associated with these rights.

\section{Takedown policy}

If you believe that this document breaches copyright please refer to the University of Manchester's Takedown Procedures [http://man.ac.uk/04Y6Bo] or contact uml.scholarlycommunications@manchester.ac.uk providing relevant details, so we can investigate your claim.

\section{OPEN ACCESS}


This document is confidential and is proprietary to the American Chemical Society and its authors. Do not copy or disclose without written permission. If you have received this item in error, notify the sender and delete all copies.

\section{Graphene liquid-enclosure for single-molecule analysis of membrane proteins in whole cells using electron microscopy}

\begin{tabular}{|r|l|}
\hline Journal: & ACS Nano \\
\hline Manuscript ID & nn-2017-052584.R1 \\
\hline Danuscript Type: & Article \\
\hline Complete List of Authors: & $\begin{array}{l}\text { Dahmke, Indra; INM - Leibniz Insitute for New Materials } \\
\text { Verch, Andreas; INM - Leibniz Institute for New Materials, } \\
\text { Hermannsdörfer, Justus; INM - Leibniz Institute for New Materials } \\
\text { Peckys, Diana; Saarland University } \\
\text { Weatherup, Robert; University of Cambridge, Engineering } \\
\text { Hofmann, Stephan; University of Cambridge, Engineering } \\
\text { de Jonge, Niels; INM - Leibniz Institute for New Materials, }\end{array}$ \\
\hline
\end{tabular}

\section{SCHOLARONE}

Manuscripts 


\section{Graphene Liquid-Enclosure for Single-Molecule}

\section{Analysis of Membrane Proteins in Whole Cells}

\section{using Electron Microscopy}

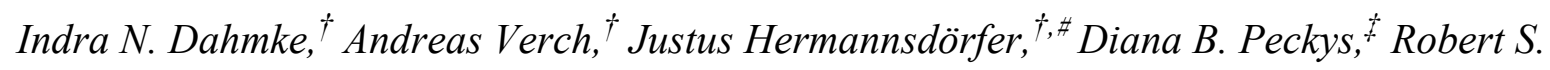

Weatherup,$^{\S}$ Stephan Hofmann ${ }^{\S}$ and Niels de Jonge $* \%, \perp$

${ }^{\dagger}$ INM - Leibniz Institute for New Materials, D-66123 Saarbrücken, Germany

$\$$ Department of Biophysics, Saarland University, D-66421 Homburg, Germany

${ }^{\S}$ Engineering Department, University of Cambridge, Cambridge CB3 0FA, United Kingdom

${ }^{\perp}$ Department of Physics, Saarland University, D-66123 Saarbrücken, Germany.

ABSTRACT Membrane proteins govern many important functions in cells via dynamic oligomerization into active complexes. However, analytical methods to study their distribution and functional state in relation to the cellular structure are currently limited. Here, we introduce a technique for studying single membrane proteins within their native context of the intact plasma membrane. SKBR3 breast cancer cells were grown on silicon microchips with thin silicon nitride windows. The cells were fixed and the epidermal growth factor receptor ErbB2 was specifically labeled with quantum dot (QD) nanoparticles. For correlative fluorescence- and liquid-phase 
electron microscopy, we enclosed the liquid samples by chemical vapor deposited (CVD) graphene films. Depending on the local cell thickness, QD labels were imaged with a spatial resolution of $2 \mathrm{~nm}$ at a low electron dose. The distribution and stoichiometric assembly of ErbB2 receptors were determined at several different cellular locations, including tunneling nanotubes, where we found higher levels of homodimerization at the connecting sites. This experimental approach is applicable to a wide range of cell lines and membrane proteins and particularly suitable for studies involving both inter- and intra-cellular heterogeneity in protein distribution and expression.

Keywords: graphene; STEM; single-molecule analysis; liquid-phase electron microscopy; tunneling nanotube; epidermal growth factor receptor; breast cancer cell

The cellular membrane and the residing proteins act as an interface for eukaryotic cells, collecting information from the environment, communicating these stimuli, and mediating the resulting cellular reaction. Membrane proteins are key players in cellular communication, working as receptors and channels to initiate, for example, cell growth or differentiation. As such, they represent about $60 \%$ of today's drug targets. ${ }^{1}$ Yet, the functional analysis of endogenous membrane proteins in their native environment, so called 'functional proteomics', including the aspects of heterogeneity in protein expression and for instance intratumoral clonal heterogeneity, remains challenging. ${ }^{2-5}$ Proteomic analyses are usually performed for lysed bulk populations of cells so that the spatial context of the proteins is lost and information is obtained about population averages only. For the study of protein function, it is essential to examine the assembly of membrane proteins at the single molecule level within its native environment of the intact plasma membrane. ${ }^{3}$ Amongst all available microscopy methods, the necessary nanometer 
spatial resolution for imaging whole cells is only achieved by electron microscopy $(\mathrm{EM})^{6-8}$ that requires extensive sample preparation such as for example plunge freezing or cryo sectioning. Several techniques for EM of intact cells in liquid have become available in recent years ${ }^{9-11}$ but these achieve a limited resolution, and require special experimental conditions as well as dedicated equipment. In recent reports, single and multiple layers of graphene were utilized to cover radiation-sensitive biological samples providing a barrier against evaporation in the EM vacuum chamber. ${ }^{12-14}$ Graphene was also shown to mitigate the effects of radiation damage in liquid-phase EM. ${ }^{12}$

Here, we demonstrate that membrane proteins labeled with nanoparticles can be imaged with scanning transmission electron microscopy (STEM) at nanometer resolution in whole cells covered by a graphene-liquid enclosure. We used chemical vapor deposited (CVD) bilayer graphene films to enclose chemically fixed, hydrated SKBR3 breast cancer cells, a commonly used ErbB2-overexpressing cell line for cancer research. ${ }^{15}$ The cells were grown on thin silicon nitride ( $\mathrm{SiN})$ membranes supported by silicon microchips and individual ErbB2 proteins in the plasma membrane were labeled with an Affibody ${ }^{16}$ to which a QD was coupled; ${ }^{5}$ these were subsequently imaged by correlative light microscopy and STEM (Figure 1). ErbB2 is a member of the epidermal growth factor receptor (EGFR) family and is found overexpressed in $20-30 \%$ of all breast cancer patients correlating with a poor prognosis. ${ }^{17}$ The assembly of ErbB2 into homoand heterodimers activates down-stream signaling and induces, for example, cell proliferation. The graphene based liquid enclosure in combination with STEM enabled us to determine the stoichiometric assembly of labeled ErbB2 while preserving the native cellular context, the intact cellular membrane, of the proteins. To evaluate the capabilities of this technique we determined the distribution of ErbB2 molecules along tunneling nanotubes (TNTs). TNTs are transient, thin, 
membranous connections between two cells that facilitate intercellular long-distance communication by transferring small molecules, membrane proteins, or even vesicles and organelles. ${ }^{18-20}$ They have been described in numerous cancerous and non-cancerous cell lines as well as in vivo. ${ }^{21,22}$ It is known that EGFR plays a key role in TNT development, ${ }^{22}$ and in the present report, we explore the potential involvement of the family member ErbB2 in the formation of TNTs. We found that our approach facilitated membrane protein analysis on a single-molecule level and thus represents a versatile method to study membrane protein distribution in subcellular regions of intact mammalian cells with nanometer spatial resolution.

\section{RESULTS}

\section{Graphene enclosure enables correlative light- and electron microscopy of QD labeled membrane proteins in whole cells. To test the applicability of graphene as a cover for STEM of} QD-labeled membrane proteins in mammalian cells, we cultivated SKBR3 breast cancer cells on microchips containing a thin silicon nitride (SiN) window (Figure 1). The microchips provide a practical support for the cells during all preparation steps. ${ }^{23}$ Once the cells had grown to the desired density, they were incubated with biotin-conjugated anti-ErbB2-Affibodies, $14 \mathrm{kDa}$ small and highly specific ErbB2-targeting proteins. The biotin-conjugated anti-ErbB2-Affibody binds to an ErbB2 epitope in a 1:1 stoichiometry. ${ }^{16}$ The cells were then fixed with paraformaldehyde to chemically crosslink membrane proteins, ${ }^{24}$ and incubated with QD-streptavidin. The fixation step prevented artificial, QD-induced, clustering of ErbB2 proteins on account of the presence of multiple streptavidin proteins per QD as well as incorporation of the QDs. ${ }^{5}$ Based on the experimental conditions, the presence of one QD was interpreted as one underlying ErbB2 protein. 
After the labeling, the cells were imaged with fluorescence microscopy in order to identify cellular regions of interest with high expression levels of ErbB2. The overlay of the differential interference contrast (DIC) channel with the fluorescence signal revealed the varying levels of ErbB2 expression in red $(655 \mathrm{~nm})$ (Figure $2 \mathrm{a})$. In a next step, the hydrated cells were covered with CVD-graphene. The transferred bilayer graphene film was immobilized on single-crystal $\mathrm{NaCl}$ support, which was then dissolved in at least 0.51 of pure water (see methods). The bilayer graphene film remained floating on the water surface and was scooped up with the cellcontaining microchip (Figure S1). Next, the microchip was left to air-dry to remove excess liquid.

The graphene enclosure was first examined using scanning electron microscopy (SEM) to detect potential faults in the graphene film (Figure 2b, S2, S3). Some samples showed cracks in the graphene enclosure (Figure S2a) or lacked the coating altogether (Figure S2b, c). This led to electrical charging of the investigated area during electron beam irradiation resulting in bright image artifacts (Figure S2b). Evacuating the air from the sample chamber for EM even led to the rupture of the membrane of cells not covered with graphene (Figure S2c). Occasionally, salt crystals formed as a result of the drying process of excess liquid (Figure S3). Microchips for which the graphene coating was successful, were next imaged by TEM or STEM at low magnifications $(1,200-2,500 \times)$ in order to map positions of cells and regions of interest for EM (Figure 2c). These recordings were spatially correlated with the fluorescence images acquired beforehand of the same region, as the overlay picture demonstrates (Figure 2c). The TNT visible in Figure 2c was selected for a further analysis at higher magnifications (Figure 2d-f) It had a length of $\sim 11 \mu \mathrm{m}$ and a diameter of $\sim 0.16 \mu \mathrm{m}$, and connected two neighboring cells. It was visible as bright elongated shape in the dark-field STEM image (Figure 2d). With high-resolution 
dark-field STEM (150,000×), single QDs were resolvable, and the assembly of ErbB2 proteins into single, paired, and higher-order cluster in the plasma membrane was detected (Figure 2e). Zooming into the selected region of Figure 2e shows the bullet-shaped CdSe cores of the QDs as bright structures (Figure $2 \mathrm{f}$ ). ${ }^{5}$

\section{Statistical analysis of ErbB2 protein distribution in the plasma membrane shows varied distribution of homodimers on the TNT. The entire TNT as well as the adjacent plasma} membrane of the connected cells were examined with STEM at a high magnification of $150,000 \times$, and the images were then stitched together to display the whole structure (Figure 3a). It can be seen that the TNT connects two cells. Its width remains unchanged in the middle part while it broadens when it reaches the neighboring cell. The locations of automatically detected QDs were marked in yellow to enhance their visibility. The number of labels (see table S1) is higher at the area of connection $\mathrm{CON} 2$ (Figure 3b), decreases over the main part and increases again at the other connection site (Table S1). At CON1, the TNT appears to end in a narrow shape touching a thicker cellular region brightly visible at the left side of Figure 3c. Many QDs appear blurred at this cellular region and were not automatically detected. This is explained by the electron beam being out of focus for the vertical locations of these QDs.

In the subsequent statistical analysis, we studied QD label distributions in two different regions, namely at the TNT's surface of the area between the cells, and at both ends in the plasma membrane at the connection $(\mathrm{CON})$ of the TNT. An example of a selected TNT area is shown in Figure $3 \mathrm{~d}$. The images analyzed in the group marked as TNT connection were those at the far left and the far-right side as marked by the dashed lines in Figure 3a. 
The functional state of the ErbB2 receptor is visible from its stoichiometric assembly into homodimers which show an active down-stream signaling in contrast to monomers. ${ }^{25,} 26$ Regarding the image analysis we take two complications into account: First, we assume the presence of monomers randomly positioned at a close distance, and secondly a labeling efficiency below $100 \%$. Therefore, we included a statistical analysis to determine the presence of homodimers. The spatial label distribution was statistically analyzed by means of the pair correlation function $g(r)$ measuring the probability of finding two labels at a certain radial distance. ${ }^{27}$ A random distribution is represented by $g(r)=1$, whereas $g(r)>1$ represents a clustering of two QDs at a certain distance from each other. The $g(r)$ curve of ErbB2 labels at the connection exhibit a peak at $r=20 \mathrm{~nm}$ (Figure 3e), and the curve converges to a value of 1 for large $r$. The observation of an inter-label distance above-random probability indicates an underlying cell-biological mechanism and the measured distance at about $20 \mathrm{~nm}$ matches the expected range of two QD labels attached to an active ErbB2 homodimer. ${ }^{5}$ For comparison, we also analyzed so called ruffled areas of multiple cells (Figure S5) and confirmed the presence of the 20 -nm peak (Figure $3 \mathrm{f}$ ) in these regions as found previously. ${ }^{5}$ Furthermore, we detected a shoulder in this peak at $50 \mathrm{~nm}$ at the connective sites of the TNT (marked with 1 in Figure 3e).

The $g(r)$ corresponding to the TNT displays a strongly reduced 20-nm peak almost within the statistical fluctuations of the curve. Instead, a new peak at $150 \mathrm{~nm}$ is present (marked with 2 in Figure 3e) consistent with the width of the analyzed TNT. The curvature along the TNT leads to a higher apparent density of labels at its edges compared to the middle, so that this peak at 150 $\mathrm{nm}$ is a measure of the TNT's width. Apart from this, the TNT curve closely resembles the ErbB2 distribution found in flat areas of the plasma membrane, in which the proteins are 
spatially distributed in a random manner and homodimers are mostly absent ${ }^{5}$ (Figure $3 f$, Figure S5).

Other samples with TNTs were studied as well. The analysis of a TNT of more than $50 \mu \mathrm{m}$ in length is exemplarily shown in Figure S4. The corresponding $g(r)$ curves exhibit similar features as Figure 3e. The 20-nm peak is visible at the connection but not on the main part of the TNT. But in addition, the connection on one side of this TNT does not show a 20 -nm peak implying that signaling active ErbB2-homodimers are only present at one connective site. The growth of a TNT from one to a next cell was observed in a live cell time-lapse light microscopy experiment (Movie S1) supporting the concept of directed TNT growth.

\section{Nanometer resolution on QD-labeled ErbB2 in graphene enclosed whole cells. An} important matter is the achievable spatial resolution in particular for thicker regions of whole, hydrated cells. The key limitation for imaging in thicker regions is scattering of the electron beam in the material surrounding the QD-labels leading to an increased background signal. Due to statistical fluctuations of this background signal, the signal-to-noise-ratio (SNR) for detection of the QDs is reduced. The SNR can be increased by using a larger electron dose but this is undesirable when imaging biological samples. To evaluate the resolution of the STEM technique for thicker regions, micrographs of cell regions with increasing thickness were recorded. Firstly, we examined the achievable spatial resolution at a low dose of $q=10 \mathrm{e}^{-} / \AA^{2}$, well below the damage threshold dose for both cryo-TEM of cells $\left(10^{2} \mathrm{e}^{-} / \AA^{2}\right)$, and the threshold dose for liquidphase environmental SEM (ESEM) of fixed cells with STEM detection $\left(10^{3} \mathrm{e}^{-} / \AA^{2}\right){ }^{28,29}$ A noise filter was applied to the images to enhance the visibility of the QD labels. The thinnest imaged area was a flat area outside of a cell (Figure 4a) but with some remainders of plasma membrane 
(Figure 4b). Several QDs are visible with strong contrast. Next, cellular regions of increasing cellular thickness were imaged of which three are shown in Figs. 4c-e. The background signal increased with increasing sample thickness resulting in a fading contrast. Nevertheless, QD labels were still distinguishable on the thickest examined cellular region of $7 \mu \mathrm{m}$ imaged with STEM (Figure 4e).

The spatial resolution was also examined for microscope settings optimized to achieve high resolution but still avoiding beam damage as much as possible but in a region near a cell (Figure 4f). Figure $4 \mathrm{~g}$ was recorded in a thin cellular region at the edge of a cell using $q=$ $9.8 \times 10^{2} \mathrm{e}^{-} / \AA^{2}$ at the onset of radiation damage found in a different study for liquid cellular specimens imaged at lower beam energy. ${ }^{29}$ The QDs appear with strong contrast and their bullet shape is visible containing one side with a sharp edge. The two QDs at the location of the asterisk were also imaged at higher magnification and dose, at which the lattice fringes of the CdSe core of the QDs became visible (Figure 4h). This image was acquired with an electron dose exceeding the mentioned radiation damage limit for biological structures and should accordingly be avoided in order to preserve the specimen. The graphene liquid enclosure, including the SiN supporting membrane, thus enables atomic resolution if the required electron dose can be applied.

The electron dose-limited spatial resolution was measured from the $25-75 \%$ edge width $\left(r_{25-75}\right)$ of line scans ${ }^{10,30}$ conducted on the imaged QDs. Figure $4 \mathrm{i}$ shows two extreme cases. The line scan over a QD in the background region (Figure $4 \mathrm{~b}$ ) exhibited a much larger peak than the background fluctuations so that the QDs are visible with high contrast. The peak was still visible at thick cellular regions (for example, Figure 4e) but then accompanied by a much larger background signal. The dose optimized spatial resolution amounted to $2.4 \mathrm{~nm}$ for sample 
thicknesses up to $1 \mu \mathrm{m}$, and decreased with larger thicknesses (Figure 4j). Although the contrast was strongly reduced in the thicker imaged region (Figure 4e), a resolution of $3 \mathrm{~nm}$ at a sample thickness of $7 \mu \mathrm{m}$ was still attained (Figure $4 \mathrm{j}$ ). Since the signal-to-noise ratio at this thickness was smaller than a factor of 3 , known as the Rose criterion needed for unambiguous detection ${ }^{30}$, the identification of nanoparticles was difficult. At sample regions exceeding this thickness, for example, over the nucleus, it was impossible to acquire images with sufficient contrast to distinguish the QDs at the used electron dose. Remarkably, the signal-to-noise-ratio seemed to be improved by the graphene coating during high magnification imaging with STEM (Figure S3d, e). This dose-optimized resolution is sufficient to distinguish individual QDs and, to determine the functional state of membrane proteins by the stoichiometric assembly of their subunits.

The measurement for resolution-optimized settings is shown as well in Figure $4 \mathrm{j}$. These data were acquired using acquired using $q \leq 9.8 \times 10^{2} \mathrm{e}^{-} / \AA^{2}$ except for the highest resolution (Fig $4 \mathrm{~h}$ ). In our experiments we achieved $1.2 \mathrm{~nm}$ of resolution for sample thicknesses up to $1 \mu \mathrm{m}$ and 1.8 $\mathrm{nm}$ for $6.5 \mu \mathrm{m}$ of water thickness.

An important advantage of the graphene coating is a reduced sensitivity to radiation damage via the quenching of excited states created in the liquid by the electron beam. ${ }^{12}$ Several series of consecutive STEM images were recorded to test the sensitivity to electron beam irradiation. Firstly, a series of 10 images was recorded at a low dose of $10 \mathrm{e}^{-} / \AA^{2}$ per image, for which the label positions did not noticeably change (Figure S6a, b). Secondly, to test for higher doses, an image series was acquired at the edge of a cell (Figure S6c, d) with a total dose of $3.1 \times 10^{3} \mathrm{e}^{-} / \AA^{2}$, which is a factor of 3 above the dose limit for liquid-phase electron microcopy at $30 \mathrm{keV}$ beam energy ${ }^{29}$ and two orders of magnitude above the dose limit for TEM of samples in amorphous ice. ${ }^{28}$ We found the deformation of the sample of dimensions of $897 \times 897 \mathrm{~nm}^{2}$ was almost 
negligible and amounted to maximal $2 \mathrm{~nm}$ or $0.2 \%$ throughout this series in total. Importantly, this deformation did not influence the relative positions of QDs at short spatial ranges, which is the relevant parameter for the examination of the functional states of the proteins. The graphene covered liquid-phase specimen is thus highly stable to the electron beam irradiation and nanometer resolution images can be recorded well within the dose range of electron beam damage.

\section{DISCUSSION}

Correlative light microscopy and STEM of whole, hydrated cells covered with graphene films enabled us to examine the distribution and stoichiometric assembly of individual ErbB2 proteins in certain cellular regions. In particular, we analyzed ErbB2 proteins at long-distance cell-cell connections between SKBR3 breast cancer cells formed by TNTs. It is known that TNTs facilitate intercellular communication by transferring small molecules, vesicles and organelles, playing a substantial role in mediating chemo-resistance in cancer cells, ${ }^{18-20,31,32}$ for example, by transferring mitochondria from endothelial cells to cancer cells. ${ }^{19}$ Two mechanisms of TNT formation involving different sets of protein complexes, the cell-dislodgment mechanism and the actin-driven protrusion, have been described, which possibly may depend on the type of TNTinitiating cell or the mode of induction. The cell-dislodgment method was found in immune cells and certain cancer cells, ${ }^{33}$ where two cells are connected via an immune-synapse or fusion and the TNT is formed by subsequent cell migration in the opposite directions. TNT formation by actin-driven protrusions was first proposed by Rustom et al. in 2004, and is induced by cell stress. $^{20}$ It is argued that either the stressed cell secrets certain molecules as a 'call-for-help' inducing TNT-formation in healthy cells ${ }^{34}$ or that the stressed cell itself grows TNTs. ${ }^{22}$ Besides

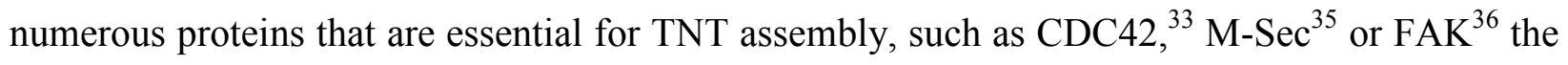


EGFR pathway, either via induction by EGF or p53, plays a central role. ${ }^{22,37}$ Since our protocol requires serum starvation of cells, we assume that the actin-driven protrusion might be the most prevalent mechanism in our set-up. Also, it is known that ErbB2 overexpression causes deformation of cell membranes into protrusions. ${ }^{38}$ Because SKBR3 cells are known to express about 50 times more ErbB2 compared to EGFR, and ErbB3 and ErbB4 are negligible in comparison, ${ }^{39}$ we, therefore, suggest that ErbB2 might play a role in the formation of TNTs in SKBR3 cells. Our results show an increased number of ErbB2 proteins as well as a higher number of homodimers at the TNT connection, which implies localized signaling of the growth factor receptors. On the TNT area between the cells we found a reduced number of labels and signaling active homodimers were absent. We propose that ErbB2 recruitment and down-stream signaling are involved in TNT formation in SKBR3 breast cancer cells.

In addition, we detected a shoulder of the $50 \mathrm{~nm}$ in the $g(r)$ curve of the connecting site of the TNT. Rustom et al., 2004 described the association of the actin-specific motor-protein myosin Va with TNTs. ${ }^{20}$ This motor-protein was found to contribute to a $50 \mathrm{~nm}$ wide fringe around actin-filaments and might interact directly or indirectly with ErbB2. ${ }^{40}$

With the capability of this technique, to quantify heterogeneity in protein stoichiometry at a single-molecule level in various cellular regions of whole cells, we revealed an association of activated ErbB2 growth factor receptors with the connecting ends of TNTs. In general, singlecell analysis is an important tool to gain understanding of the fundamental biology of cells. Furthermore, it is important for biomedical research because a hallmark of human cancers is heterogeneity of cells considered to be the origin for primary and acquired chemoresistancies. ${ }^{41}$ State-of-the-art methods of single-cell proteomics in the field of flow cytometry and gel electrophoresis, however, lack the possibility to gain information about underlying cellular 
structures. ${ }^{3,}{ }^{42}$ Existing light microscopy methods on the other hand, do not provide sufficient resolution to directly image the stoichiometric assembly of protein complexes as needed to examine their function, ${ }^{42,43}$ although clustering can be examined at the single cell level. ${ }^{44}$ For example, super resolution fluorescence microscopy of QD-labeled epidermal growth factor receptors was accomplished with an order of magnitude lower spatial resolution for which it becomes challenging to draw conclusions on the stoichiometric state of the receptor, and also high resolution information about the cellular ultrastructure as needed to resolve the TNT cannot be provided. $^{45}$ Indirect optical techniques, such as Förster Resonance Energy Transfer (FRET), may result in artifacts. ${ }^{5}$ For example, labeled proteins placed back-to-back may result in a stronger FRET-signal than true dimers. Also artifacts may arise, if the dimensions of the protein complexes supersede the FRET distance, (Piston \& Kremers, 2007) Certain other indirect fluorescence techniques may require abnormally membrane low protein densities of $<1$ per $\mu \mathrm{m}^{2}$, or use genetically modified target proteins with a fluorescent tag. ${ }^{46}$ Cryo-TEM and STEM are capable of examining thin regions of whole cells in frozen hydrated state ${ }^{6-8,28,47}$ but these techniques are used in practice for high resolution studies of the ultrastructure in a few selected cellular regions or sections. Cryogenic sample preparation and sample handling add substantial difficulties in studying large numbers of cells as required for valid statistical evaluations or to find rare structural features, such as TNTs.

In contrast, liquid-phase electron microscopy offers the opportunity to easily handle and image series of intact, hydrated cells. ${ }^{48}$ However, the techniques reported in the literature to date, require special experimental configurations in order to achieve the spatial resolution which is necessary for single-molecule analysis. For example, STEM imaging of whole COS7 cells in a liquid enclosure formed by two silicon nitride windows required the total sample to be thinner 
than $7 \mu \mathrm{m}$, which limits its usage. ${ }^{10}$ In practice, many cellular samples of thin cells contain thicker areas with stacked liquid cells and it is often impossible to obtain a sufficiently thin liquid enclosure. Moreover, the resolution has been limited by the thick liquid layer resulting in difficulties to discern quantum dot labels. The graphene enclosure instead, adjusts to the changes in liquid thickness over varying areas of the cell. Another method, ESEM coupled with STEM detection $^{49}$ is capable of handling thicker specimens but only achieves nanometer resolution for sample regions thinner than $0.5 \mu \mathrm{m}$, and exhibits a lower resolution than STEM. $^{11}$ Alternatively, cells in liquid can be examined by correlative light- electron microscopy using cell culture dishes containing electron transparent windows ${ }^{50}$ in SEM, or using an SEM with an integrated optical lens. ${ }^{51}$ However, both techniques use back-scatter detection and the achievable spatial resolution is in the range of $10-20 \mathrm{~nm}$, which is insufficient to resolve the individual subunits of membrane protein complexes. Without the capability to resolve the protein subunits to determine their functional state, these techniques have only limited advantages over super resolution light microscopy. $^{44}$

By using a graphene-liquid enclosure for the study of single proteins in whole cells, we demonstrated nanometer spatial resolution at an electron dose of $10 \mathrm{e}^{-} / \AA^{2}$ even for the thicker cellular regions. This resolution is sufficient to distinguish ErbB2 monomers from dimers, and to potentially identify the stoichiometry of many other types of membrane protein complexes. Besides its optical- and electron-transparent properties, the flexibility of the graphene film enables imaging of samples for which the maximum thickness exceeds the height at the sampling area. Noticeable radiation damage was not observed for a tested higher electron dose of up to $3.1 \times 10^{3} \mathrm{e}^{-} / \AA^{2}$ for a thin region which might be due to the conductive properties of graphene. On account of the low electron dose it might be feasible to study unfixed cells as well but that would 
require a different labeling protocol. A further technical advantage is that the graphene-liquid enclosure is useable with standard electron microscopes and specimen holders, avoiding the need for dedicated liquid specimen holders or for an environmental chamber.

\section{CONCLUSIONS}

STEM of fixed, hydrated cells in a graphene liquid-enclosure achieves nanometer spatial resolution even for electron doses well below the measured radiation damage threshold of $3.1 \times 10^{3} \mathrm{e}^{-} / \AA^{2}$. It provides information about molecular assemblies in cells by its capability to locate membrane proteins at the single-molecule level and to analyze them within the context of specific cellular regions. The molecular distribution of ErbB2 was analyzed at TNTs and the adjacent plasma membrane of the connected cells. It was found that signaling active ErbB2 homodimers were present at the connection side of the two analyzed TNTs and the adjacent part of the cells, while those were absent from the main TNT's body. For one TNT, the connection side contained homodimers, while those were not present at the other connections. These observations imply an association of ErbB2 with TNTs in SKBR3 cancer cells. The described microscopy technique allows for the study of labeled membrane proteins in their native liquid environment via a range of microscopy modalities including DIC light microscopy, fluorescence microscopy, SEM, TEM, and STEM. It is applicable in principle to all membrane proteins for which specific labels are available, as well as other types of cells or biological specimens. This makes the graphene liquid-enclosure a versatile technique for the analysis of membrane proteins in whole, eukaryotic cells in liquid. 


\section{METHODS}

Cell culture and labeling of ErbB2 on SKBR3 breast cancer cells. If not indicated otherwise, all cell culture media, supplements and chemicals where purchased from LifeTechnologies. Human breast cancer SKBR3 cells (ATCC ${ }$, HTB-30 ${ }^{\mathrm{TM}}$ ), overexpressing ErbB2, were cultured in $25 \mathrm{~cm}^{2}$ cell culture flasks (Greiner Bio-One, Cellstar ${ }^{\circledR}, \mathrm{TC}^{\mathrm{TM}}$ ) with Dulbecco's Modified Eagle's Medium GlutaMAX ${ }^{\mathrm{TM}}$ (high glucose and pyruvate, DMEM) containing $1 \%$ non-essential amino acids and 10\% heat inactivated Fetal Bovine Serum (FBS) under standard cell culturing conditions at $37^{\circ} \mathrm{C}$ and $5 \% \mathrm{CO}_{2}$. This cell line serves as a model system of ErbB2+ breast cancer ${ }^{15}$. For correlative fluorescence and electron microscopy, cells were seeded 2 days prior to imaging on custom-made SiN-microchips ${ }^{23}$ of dimensions: $2.0 \times 2.6 \times 0.3 \mathrm{~mm}^{3}, \mathrm{SiN}$-window: $0.40 \times 0.06 \mathrm{~mm}^{2}$ of $50 \mathrm{~nm}$ thickness (DENS solutions). Notice that microchips of other dimensions fitting a standard TEM specimen holder may also be used. However, the larger the width of the SiN membrane window is, the larger the risk of breaking. To our experience, the window should not exceed the width of $0.15 \mu \mathrm{m}$ for $50 \mathrm{~nm}$ thick $\mathrm{SiN}$ windows. The length is not critical. Standard $3 \mathrm{~mm}$ grids also work but are more delicate to handle compared to the microchips. Before seeding the cells, the microchips were subjected to $\mathrm{ArO}_{2}$-plasma cleaning for $5 \mathrm{~min}$, and then coated with poly-L-lysine (0.01\%, Sigma-Aldrich) for $5 \mathrm{~min}$ at room temperature (RT) and washed twice with phosphate buffered solution (PBS). This step was followed by a fibronectin-coating $(15 \mu \mathrm{g} / \mathrm{ml}$, Sigma-Aldrich) under the same conditions. Immediately thereafter, the microchips were transferred to a 96-well-plate (Greiner Bio-One, Cellstar $\left.{ }^{\circledR}\right)$, with one microchip per well and covered with $100 \mu$ l of FBS-free DMEM. Next, SKBR3 cells were harvested with CellStripper (Corning), diluted to 100,000 cells per ml and $100 \mu \mathrm{l}$ of the prepared cell-suspension were added to each well. After 2-3 h of incubation 
under standard culture conditions, the number of SKBR3 cells that settled on the SiN-window was checked and microchips containing at least 15-20 cells per window were transferred to new wells pre-filled with $200 \mu 1$ of DMEM for further cultivation. Prior to the experiment, cells were serum-starved overnight in FBS-free DMEM to enhance membrane-expression of ErbB2. For the QD-labeling of cells, chips were rinsed once in GS-BSA-GEL-PBS (1\% goat-serum (GS), Rockland Immunochemicals Inc; 1\% BSA (molecular biology-grade albumin fraction V, Carl Roth GmbH-Co. KG); 0.1\% cold water fish skin gelatin Sigma-Aldrich; in PBS (pH 7.4)) and then incubated in the same solution for $5 \mathrm{~min}$ at $37^{\circ} \mathrm{C}$ to block unspecific binding of biotinconjugated anti-ErbB2-Affibodies ((ZERBB2:477)2, ErbB2-AFF-B). Next, microchips were incubated for $10 \mathrm{~min}$ at $37^{\circ} \mathrm{C}$ with $200 \mathrm{nM}$ ErbB2-AFF-B in GS-BSA-GEL-PBS and after washing twice with 1\%-BSA-PBS, once in PBS and once in cacodylate-buffer $(\mathrm{CB}, 0.1 \mathrm{M}$ sodium cacodylate trihydrate, Carl Roth $\mathrm{GmbH}$, and $0.1 \mathrm{M}$ saccharose, $\mathrm{pH} 7.4$ ), the cells were fixed at RT with 3\% Formaldehyde (Electron Microscopy Sciences) in CB to prevent QDinduced clustering of ErbB2-molecules. Subsequently, cells were rinsed once with CB, three times with PBS and incubated in 0.1 M glycine in PBS for 2 min. After two additional washes with PBS, cells were incubated in $5 \mathrm{nM}$ streptavidin-conjugated Qdot 655 (Life Technologies, Carlsbad, CA, USA) in $40 \mathrm{mM}$ borate buffer (sodium tretraborate boric acid, Sigma-Aldrich, $\mathrm{pH}$ 8.3) at RT for $12 \mathrm{~min}$. Next, cells were washed three times in 1\% BSA-PBS and subjected to fluorescence imaging. After that, the cells were washed once with $\mathrm{CB}$ and fixed for $10 \mathrm{~min}$ at RT with $2 \%$ glutaraldehyde (electron-microscopy grade, Carl Roth GmbH-Co. KG) in ${ }^{5}$ order to increase stability of the samples under electron beam radiation. The combined fixation with paraformaldehyde and glutaraldehyde crosslinks and immobilizes proteins in the plasma membrane. ${ }^{24}$ Further details on the labeling method for ErbB2 in SKBR3 cells using specific 
Affibodis and QDs including control experiments are described elsewhere. ${ }^{5}$ Also, practical details of the protocol are reported as video publication. ${ }^{23}$

Graphene deposition. Mono-layer graphene was grown on $25 \mu \mathrm{m}$ thick polycrystalline CU films by CVD. ${ }^{52,53}$ The $\mathrm{Cu}$ foil was untreated prior to growth leading to domain sizes of $\sim 10 \mu \mathrm{m}$ in lateral dimensions showing an average Raman $\mathrm{D} / \mathrm{G}$ peak intensity ratio of ${ }^{54}<5 \%$. It was covered with a polymer by spin coating (polymethylmethacrylate, 4 wt $\%$ in anisole, $950 \mathrm{~K}$ molecular weight) and the $\mathrm{CU}$ catalyst was removed from the graphene by etching with $\left(\mathrm{NH}_{4}\right)_{2} \mathrm{~S}_{2} \mathrm{O}_{8}$. The as-released polymer-supported graphene was rinsed in Milli-Q water to eliminate residual etchant. It was then lifted out onto the surface of a second, slightly larger piece of $\mathrm{Cu}$ film that had undergone the same mono-layer graphene CVD process. The stack was dried at $\sim 50^{\circ} \mathrm{C}$ to obtain a bilayer graphene film on $\mathrm{Cu}$. Now the $\mathrm{Cu}$ was etched as before. The polymer-supported bilayer graphene was rinsed and then floated on an aqueous solution saturated with $\mathrm{NaCl}$, allowing it to be lifted out onto the surface of a cleaved single crystal of $\mathrm{NaCl}$ (Structure Probe, Inc.), without significant dissolution of the substrate. The sample was then dried at $\sim 50^{\circ} \mathrm{C}$, and the polymer was dissolved by immersion in acetone. For transfer of the graphene bi-layer films onto the hydrated cells grown on microchips, the graphene- $\mathrm{NaCl}$ crystals were carefully placed on the surface of de-salinized water. After the underlying $\mathrm{NaCl}$ was dissolved completely, the freely floating graphene film was lifted out with the microchip using a pair of Teflon-coated forceps (Figure S1). Afterwards, the positioning of the graphene film over the SiN-window was verified with a binocular and carefully corrected if necessary. Next, the microchip was fixed to holder and left for air drying at RT for about $5 \mathrm{~min}$. The integrity of the graphene film on cells was checked by scanning electron microscopy. Only cells covered by an undamaged graphene film were selected for further investigation. 
Fluorescence microscopy. Cells grown on microchips were imaged with an inverted light microscope (Leica DMI 6000B) after fixation with formaldehyde and deposition of graphene. For this purpose, the microchips were placed in a plasma-cleaned cell culture dish with a glass bottom (35 $\mathrm{mm}$ in diameter, MatTek coop.) and imaged with a 40× objective (HCX PL Fluo TAR L, 40×/0.60, dry, Leica) in DIC and fluorescence mode (filter cube: excitation: 340-380 nm, DIM: $400 \mathrm{~nm}$, emission: $425 \mathrm{~nm} \mathrm{LP).} \mathrm{Images} \mathrm{were} \mathrm{acquired} \mathrm{employing} \mathrm{the} \mathrm{LAS} \mathrm{FX}$ operational software (Leica) and to produce overview pictures of the complete SiN window these were manually stitched together.

Scanning electron microscopy. Graphene-covered cells on a microchip were imaged with a SEM in standard secondary electron detection mode (Everhart-Thornely detector) at $10.00 \mathrm{keV}$ beam energy (FEI Quanta 250 FEG). The microchips were mounted on pin stubs covered with carbon tape fixed in a multi-pin holder. Images were captured at 1,000-18,000 times magnification, working distance of 6-10 mm, a pixel dwell time of $20 \mu \mathrm{s}$, a condensor lens aperture size of $30 \mu \mathrm{m}$, and beam current of $0.1 \mathrm{nA}$. The sample stage was slightly tilted $\left(-1^{\circ}\right)$ and the operational vacuum was run at $6.34 \times 10^{-4}-1.05 \times 10^{-3} \mathrm{~Pa}$.

(Scanning) transmission electron microscopy. (S)TEM images were acquired with a transmission electron microscope (JEM-ARM 200F, JEOL) equipped with a cold field emission gun and a STEM probe corrector (CEOS GmbH). The microchip was mounted on a standard single tilt TEM sample holder (JEOL), and the sample was imaged with an electron beam of 200 $\mathrm{keV}$. In STEM mode, images were recorded with a pixel dwell time of $\tau=20 \mu \mathrm{s}$. The electron probe size was 6c (aperture CL2-3 with $20 \mu \mathrm{m}$ diameter) with a probe current of $I_{p}=20 \mathrm{pA}$ (spot 6c) with a beam convergence angle of $\alpha=13 \mathrm{mrad}$, or $I_{p}=44 \mathrm{pA}$ (spot (2c). The high-angular annular dark field detector was used for ADF STEM imaging, with a camera length of $8 \mathrm{~cm}$ 
leading to a detector opening semi-acceptance angle of $68 \mathrm{mrad}$. The latter angle refers to the collection area of the detector. For liquid thickness measurements, the current passing through the detector was measured. The corresponding semi angle was measured and amounted to 43 mrad. The image size was $1024 \times 1024$ pixels unless specified otherwise. For most recorded images, the STEM probe size was much smaller than the pixel size, and the pixel size was chosen to reduce the dose per pixel.

In TEM mode the images were recorded at corresponding magnifications with a GIF CCD camera (Gatan,) and an exposure time of $3.21 \mathrm{~s}$.

Particle analysis. For the detection of QD-labeled ErbB2 membrane proteins in EM pictures our group programmed an automated procedure ${ }^{5}$ in ImageJ (NIH). First, a Gaussian filter with a radius of 1 pixel was applied for noise-filtering. Potential variations in the image background were filtered by using a Fourier filter. Next, the image was binarized applying an automated threshold with maximal entropy settings. Bin width was set to $5 \mu \mathrm{m}$ and particles with a size $>$ $10 \mathrm{~nm}$ were taken into account by the program. Contamination particles much larger than the QD labels were present in some images. These were greyed out manually in order to avoid the triggering of the particle detection at their corners.

To conduct the subsequent statistical analysis by pair correlation function $\mathrm{g}(\mathrm{r})$, a locally designed software tool in $\mathrm{C}++$ was applied. ${ }^{5}$ The pair correlation function was defined as: ${ }^{27}$

$$
g(r)=\frac{1}{\pi \rho^{2} r \gamma(r)} \sum_{i=1}^{N} \sum_{j=i+1}^{N} k\left(r-\left|\boldsymbol{x}_{i}-\boldsymbol{x}_{j}\right|\right)
$$

with $r$ standing for the radial distance, $\rho$ the labeling density in the image. The covariance function $\gamma$ and the kernel $k$ are defined elsewhere. ${ }^{5,}{ }^{27}$ The modulus $\left|\mathbf{x}_{\mathrm{i}}-\mathbf{x}_{\mathrm{j}}\right|$ characterizes the distance between two points $\mathrm{i}$ and $\mathrm{j}$, with $x$ indicating the two-dimensional coordinates $(\mathrm{x}, \mathrm{y})$ of a 
particle in the image. For this analysis, the positions of the QD-labeled membrane proteins were assumed to be located in one plane. With the aid of the software tool a histogram of $r$ with a bin width set to $5 \mathrm{~nm}$ was plotted, and the value of $g(r)$ calculated for each bin $r$. To obtain an optimal balance between a clear-cut response and the lowest level of fluctuation of the calculated plots, we adjusted the bandwidth to $10 \mathrm{~nm}$. The QD-label distribution was analyzed for different groups obtained at different cellular regions. A minimum distance of $10 \mathrm{~nm}$ was required in the analysis in order to avoid artifacts from occasionally overlapping nanoparticles. Overlapping images areas were excluded from the analysis by manual cropping of images. To select TNT areas, individual images were rotated such that the TNT became oriented horizontal and the image was cropped such that a band with a width of $\sim 100 \mathrm{~nm}$ remained at both sides of the TNT (Figure 3d). The sides were cropped to avoid overlap between images.

Calculation of resolution in STEM images. To determine the resolution achieved in STEMrecorded images optimized for low electron dose, we used the calculation of the $25-75 \%$ edge width of line scans drawn from QD labels at selected cellular positions. ${ }^{10,30}$ A Gaussian filter with a radius of 1 pixel was applied for noise-filtering. The line scans were obtained with Image $\mathrm{J}(\mathrm{NIH})$ for a line width of 3 . For each image acquired at a certain sample thickness, five randomly chosen QD labels, which were clearly identifiable as bullet-shaped particles, were selected, and a line was drawn perpendicular to the long side. The average of the background level was set to zero in the line scan at the left side of the peak. Thisbackground level was not always flat but sometimes gradually changed from the left- to the right side of the line scan, due to the increasing cell thickness which in turn increased the background signal. Therefore the values at both sides were determined and the resulting mean value taken as described later. Next, the data was normalized so that the peak level represented a value of 1 . The resolution $\delta$ was 
calculated from the $25-75 \%$ edge widths of the peaks over QDs. Values for both the left- and the right side of the peaks were determined, and the mean values of all five particles at a specific sample thickness were averaged. The error margin was determined from the standard deviation. The resolution measured for microscope settings optimized for high resolution, was measured from the sharp edge of a QD and averaging two measurements per image.

Determination of the sample thickness. The thickness of the specimen at each imaged location was determined based on the probe current transmitted through the opening of the ADF detector. The sample thickness was calculated using the following equation for elastic scattering including both the sample and the SiN membrane: ${ }^{55}$

$$
\frac{I_{\text {screen }}}{I_{0}} \cong \exp -\left(\frac{t_{\text {SiN }}}{l_{\text {SiN }}}+\frac{t_{\text {sample }}}{l_{\text {sample }}}\right)
$$

with $I_{0}$ the current density measured on the phosphor screen of the electron microscope for vacuum (no sample) and $I_{\text {screen }}$ the current density measured with a sample inserted. The current at the phosphor screed passed through the opening of the ADF detector and so measures the nonscattered fraction of the electron beam. The thickness of the SiN window was $t_{S i N}=50 \mathrm{~nm}$. The total sample thickness was referred to as $t_{\text {sample. }}$ The electron mean free path length $l_{S i N}$ measures elastic scattering into an opening semi angle $\beta=43 \mathrm{mrad}$ or larger for amorphous $\mathrm{Si}_{3} \mathrm{~N}_{4}$, which can be calculated using equations described elsewhere ${ }^{10}$. The density for amorphous $\mathrm{Si}_{3} \mathrm{~N}_{4}$ was $\rho$ $=3.2 \mathrm{~g} / \mathrm{cm}^{3}$, the atomic weight $W=20 \mathrm{~g} / \mathrm{mol}$ and the square average atomic number ${ }^{56}<Z>=\sqrt{ }($ $\mathrm{Z}_{\mathrm{Si}}{ }^{2}+\mathrm{Z}_{\mathrm{N}}{ }^{2}$ ) $=10.6$, leading to a value of $l_{S i N}=0.89 \mu \mathrm{m}$. Assuming the sample consisted mostly of water, and using the square average $<Z>=4.7$ of water, ${ }^{57,58}$ it follows that $l_{\text {sample }}=4.1 \mu \mathrm{m}$. This method is accurate within $20 \%$ compared to thickness measurements via sample tilting for micrometers-thick liquid layers. ${ }^{58}$ Note, that the actual thickness may have differed because the 
density of protein is higher-, and the density of lipid is lower than that of water. Equation 2 can be solved to obtain the sample thickness as:

$$
t_{\text {sample }}=\left(-\ln \frac{I_{\text {screen }}}{I_{0}}-\frac{t_{\text {SiN }}}{l_{\text {SiN }}}\right) l_{\text {sample }}
$$

Calculation of the electron dose during STEM imaging. The average electron dose $q$ applied during STEM imaging was approximated from:

$$
q=\frac{I_{p} \tau}{e d^{2}}
$$

per image by the division of the product of the probe current $I p$ and the pixel dwell time $\tau$ by the product of the elementary charge $e$ and the pixel size $d$. 


\section{FIGURES}
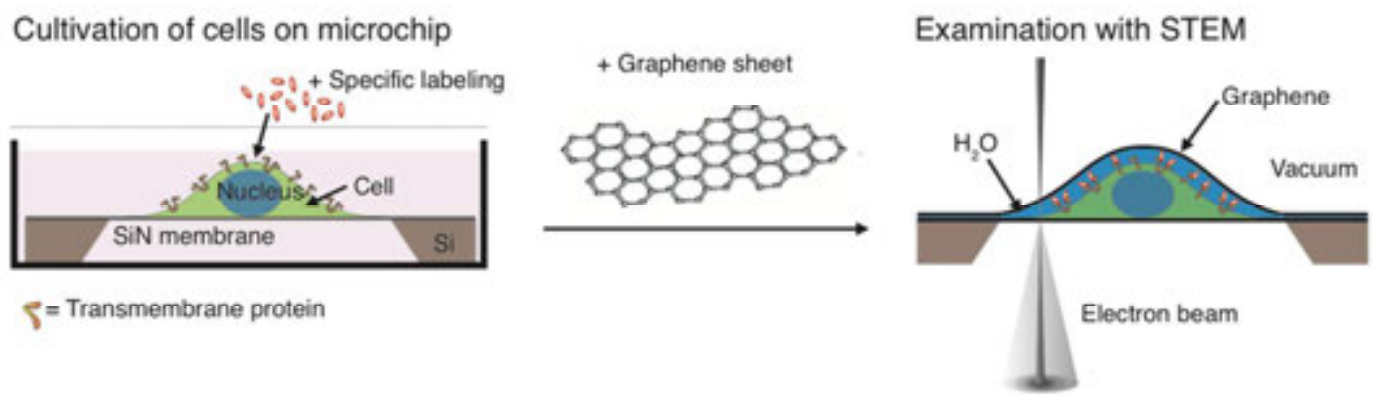

Figure 1. Scanning transmission electron microscopy (STEM) of quantum dot (QD) labeled ErbB2 proteins in graphene-enclosed, hydrated cells. Schematic of the experimental approach, showing a eukaryotic cell (green), cultivated on a silicon microchip with a silicon nitride (SiN)window in a cell culture dish. After the specific labeling of ErbB2 proteins (orange) with QDs (red), the hydrated fixed cells are coated with a graphene sheet, and subsequently studied with electron microscopy. 


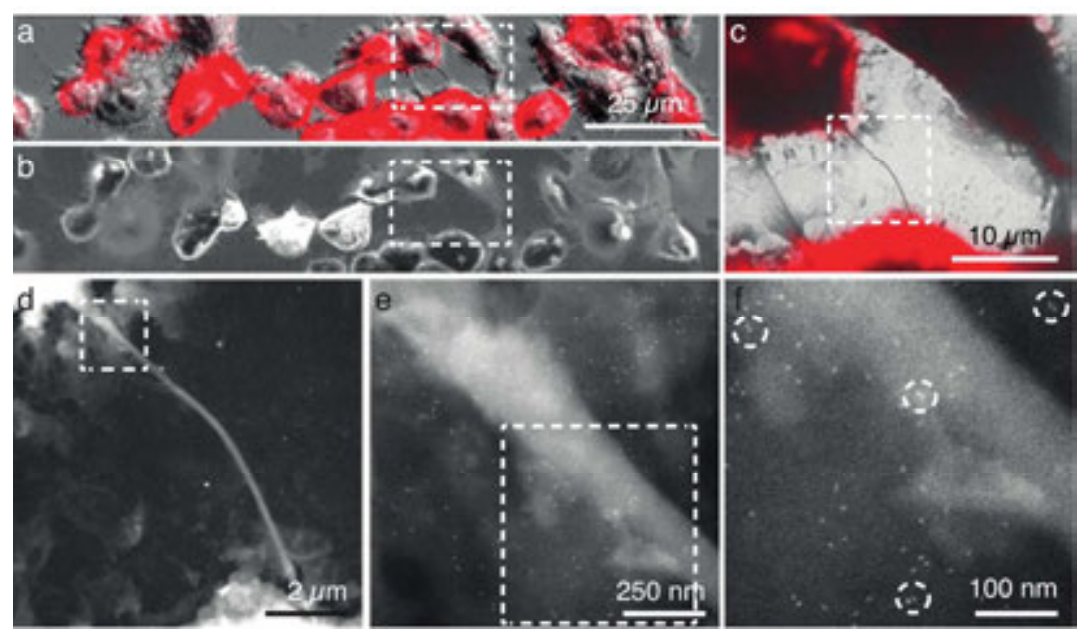

Figure 2. Correlative fluorescence- and electron microscopy of QD-labeled ErbB2 proteins in graphene-covered, hydrated SKBR3 breast cancer cells. (a) Overlay image of fluorescence- and differential interference contrast (DIC) images of QD-labeled ErbB2 proteins (red) in the plasma membrane of SKBR3 breast cancer cells cultured on a microchip. (b) Corresponding scanning electron microscopy (SEM) overview image showing graphene-covered cells in light grey. Cracks in the graphene appear dark. Non-covered cells appear in white presumably due to electrical charging. (c) Overlay of fluorescence image and low magnification transmission electron microscopy (TEM) image $(2,500 \times)$ of the region enclosed by the dashed lines in a-b. (d) Dark-field scanning transmission electron microscopy (STEM) image of the region enclosed by the dashed line in c showing the adjacent cells and the connecting tunneling nanotube (TNT) in white. (e) High resolution STEM image of TNT region marked in d. Individual QDs are visible as bright dots. The image was acquired using a magnification of $M=150,000 \times$, a pixel size of $d$ $=1.2 \mathrm{~nm}$, a probe current of $I_{p}=20 \mathrm{pA}$, and an electron dose of $q=17 \mathrm{e}-/ \AA^{2}$. (f) Enlargement of detail marked in STEM image e. The QDs are now identifiable as bright bullet-shaped dots arranged as single, paired and clustered particles. Exemplary pairs of labels, indicating ErbB2 homodimers, are marked with circles. 


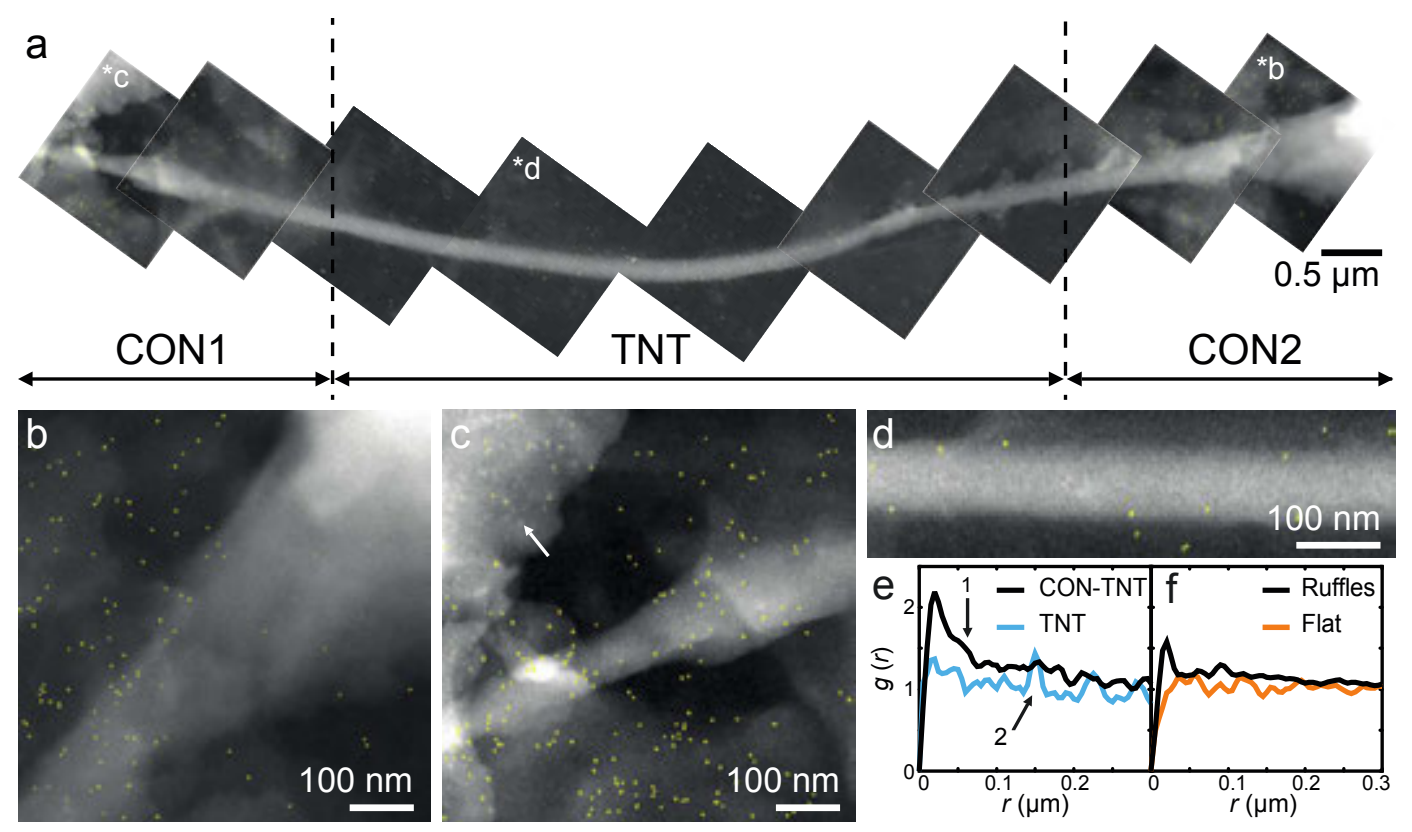

Figure 3. STEM images of entire TNT. (a) Stitched STEM images recorded at $150,000 \times$ reveals the distribution of QD-labeled ErbB2 molecules on an entire TNT, and the two areas of the TNT were it connects to the cells. The automatically detected QDs are highlighted in yellow. Dashed lines mark the borders between the analyzed areas of connection area $(\mathrm{CON})$ and the main section of the TNT between both cells. The images were acquired with the same settings as used for Figure 2e. (b) Image of TNT connection. Due to the curved surface of the TNT the QD-labels in the right part of CON 2 where out of focus and thus not automatically detected. The image is marked with $* \mathrm{~b}$ and rotated in a. Image acquired with $d=1.2 \mathrm{~nm}$. (c) Rotated image of TNT connection at the location where the TNT structure appears to terminate (marked with $*_{\mathrm{c}}$ in panel a). The arrow points to an example of a QD appearing blurred, being in a different focal plane than the TNT. (d) Cropped and rotated image of a section of the TNT marked with *d in panel a. (e) Pair correlation function $g(r)$ as function of radial pair distance $r$ determined for the images with CON marked in a, and for the cropped images of the TNT surface. (f) $g(r)$ for ruffled and flat plasma membrane regions of several cells not shown. 

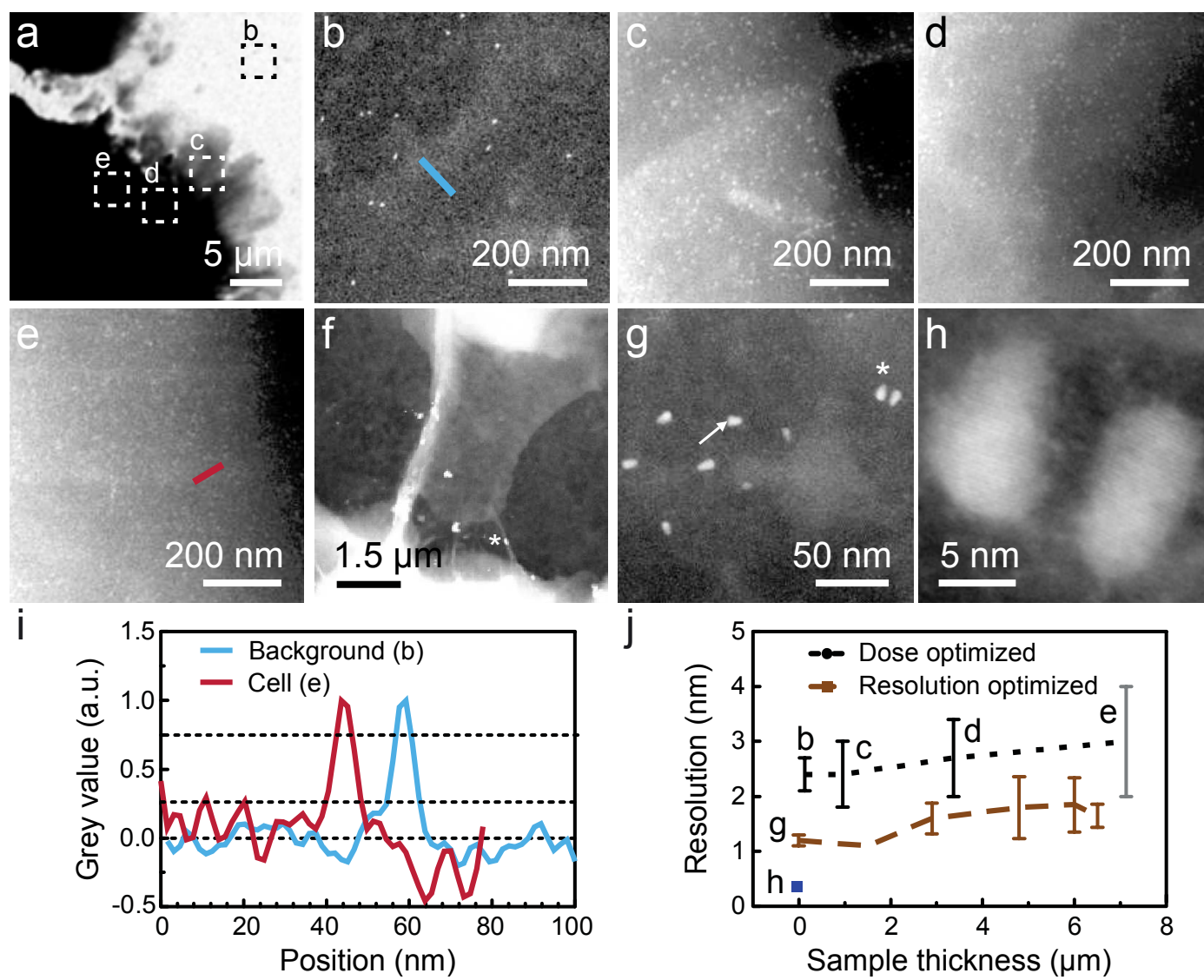

Figure 4. Spatial resolution obtained on Quantum Dots (QDs) in STEM images in relation to the sample-thickness of graphene covered, hydrated cells. (a) Overview bright field STEM image acquired with $M=2.500 \times$. (b-e) STEM images showing individual QDs recorded regions of increasing sample thickness of $\sim 0,1,3$, and $7 \mu \mathrm{m}$ in addition to the thickness of the SiN membrane. The signal-to-noise-ratio decreased with increasing thickness, and the background signal varies over the images reflecting thickness and density variations of the cell. The images were acquired for low dose settings using $M=120,000 \times, d=1.6 \mathrm{~nm}, I_{p}=20 \mathrm{pA}$, and $q=10 \mathrm{e}^{-}$ $/ \AA^{2}$. A noise filter was applied to the images, and cropped regions are shown. The locations of the images are indicated in panel a. (f) Dark-field overview STEM image $(2048 \times 2048$ pixels $)$ obtained using $M=20,000 \times$. (g) STEM image of QDs acquired with settings optimized for high resolution in a thin sample region, using $M=400,000 \times, d=0.24 \mathrm{~nm}, I_{p}=44 \mathrm{pA}$, and $q=9.8 \times 10^{2}$ 
$\mathrm{e}^{-} / \AA^{2}$. The QDs exhibit a bullet shape with a sharp edge at one side, for example at the arrow. The location of the image is indicate with the * in panel g. (h) High resolution image of two QDs revealing the lattice fringes of the CdSe cores acquired with $M=6,000,000 \times, d=0.32 \AA, I_{p}=44$ pA, and $q=5.4 \times 10^{4} \mathrm{e}^{-/} \AA^{2}$. The same QDs were imaged as indicated with the $*$ in $\mathrm{g}$. (i) Plots of two line scans over QDs displaying the grey values as the function of position for one exemplary QD recorded in a background region indicated with the blue line in $b$, and for the thickest cellular region were QDs were still distinguishable (red line in e). The signal level of the background was set to zero and the peak level to 1 . The dotted lines indicate the zero-, $25 \%$-, and 75\%-levels. (j) Graph showing the spatial resolution as function of the sample thickness for both a dose-optimized-, and a resolution-optimized data acquisition. The data points of the low dose curve correspond to the images a-d as indicated. The data point at (e) is associated with a low signal-to-noise ratio. The dashed lines are guides to the eye. 


\title{
ASSOCIATED CONTENT \\ Conflict of Interest: The authors declare no competing financial interest.
}

Supporting Information: (Table S1) Number of analyzed files, particles and calculated densities; (Figure S1) graphene depostition on cells; (Figure S2) potential imaging artifacts; (Figure S3) characteristics of graphene-covered and non-covered samples; (Figure S4) additionally imaged and analyzed TNT; (Figure S5) Images of flat and ruffled cell regions; (Figure S6) QDdisplacement during STEM imaging; (Video S1) TNT dynamics in living SKBR3 cells (.avi).This material is available free of charge via the ACS Publications website: http://pubs.acs.org.

\section{AUTHOR INFORMATION}

\section{Corresponding Author}

*E-mail: niels.dejonge@1eibniz-inm.de.

\author{
Present Addresses \\ ${ }^{\#}$ Present address: Nanoinitiative Bayern GmbH, 97074 Würzburg, Germany
}

\section{Author Contributions}

Experiments were designed by I.N.D., J.H, S.H., and N.J., carried out by I.N.D., J.H., A.V., R.S.W., and D.B.P., and analyzed by I.N.D and N.J.. All authors contributed to the writing of the manuscript. 


\section{ACKNOWLEDGMENT}

We thank S. Smolka and T. Trampert for help with the experiments, and E. Arzt for his support through INM. Research supported by the Leibniz Competition 2014, and by the Deutsche Forschungsgemeinschaft (SFB1027 (C7)). S. H. acknowledges funding from the EPSRC (EP/K016636/1). R.S.W. acknowledges a Marie Skłodowska-Curie grant (no. 656870-ARTIST) from the EU Horizon 2020 program.

\section{REFERENCES}

1. Arinaminpathy, Y.; Khurana, E.; Engelman, D. M.; Gerstein, M. B. Computational Analysis of Membrane Proteins: The Largest Class of Drug Targets. Drug Discov. Today 2009, $14,1130-1135$.

2. Burrell, R. A.; Swanton, C. Tumour Heterogeneity and the Evolution of Polyclonal Drug Resistance. Mol. Oncol. 2014, 8, 1095-1111.

3. Chen, X.; Love, J. C.; Navin, N. E.; Pachter, L.; Stubbington, M. J.; Svensson, V.; Sweedler, J. V.; Teichmann, S. A. Single-Cell Analysis at the Threshold. Nat. Biotechnol. 2016, 34, 1111-1118.

4. Kolch, W.; Pitt, A. Functional Proteomics to Dissect Tyrosine Kinase Signalling Pathways in Cancer. Nat. Rev. Cancer 2010, 10, 618-629.

5. Peckys, D. B.; Korf, U.; de Jonge, N. Local Variations of Her2 Dimerization in Breast Cancer Cells Discovered by Correlative Fluorescence and Liquid Electron Microscopy. Sci. Adv. 2015, 1 , e1500165. 
6. Wolf, S. G.; Houben, L.; Elbaum, M. Cryo-Scanning Transmission Electron Tomography of Vitrified Cells. Nat. Methods 2014, 11, 423-428.

7. Kourkoutis, L. F.; Plitzko, J. M.; Baumeister, W. Electron Microscopy of Biological Materials at the Nanometer Scale. Annu. Rev. Mater. Res. 2012, 42, 33-58.

8. Hohmann-Marriott, M. F.; Sousa, A. A.; Azari, A. A.; Glushakova, S.; Zhang, G.; Zimmerberg, J.; Leapman, R. D. Nanoscale 3d Cellular Imaging by Axial Scanning Transmission Electron Tomography. Nat. Methods 2009, 6, 729-731.

9. Nishiyama, H.; Suga, M.; Ogura, T.; Maruyama, Y.; Koizumi, M.; Mio, K.; Kitamura, S.; Sato, C. Atmospheric Scanning Electron Microscope Observes Cells and Tissues in Open Medium through Silicon Nitride Film. J. Struct. Biol. 2010, 169, 438-449.

10. de Jonge, N.; Peckys, D. B.; Kremers, G. J.; Piston, D. W. Electron Microscopy of Whole Cells in Liquid with Nanometer Resolution. Proc. Natl. Acad. Sci. 2009, 106, 2159-2164.

11. Peckys, D. B.; Baudoin, J. P.; Eder, M.; Werner, U.; de Jonge, N. Epidermal Growth Factor Receptor Subunit Locations Determined in Hydrated Cells with Environmental Scanning Electron Microscopy. Sci. Rep. 2013, 3, 2626: 2621-2626.

12. Cho, H.; Jones, M. R.; Nguyen, S. C.; Hauwiller, M. R.; Zettl, A.; Alivisatos, A. P. The Use of Graphene and Its Derivatives for Liquid-Phase Transmission Electron Microscopy of Radiation-Sensitive Specimens. Nano Lett. 2017, 17, 414-420.

13. Park, J.; Park, H.; Ercius, P.; Pegoraro, A. F.; Xu, C.; Kim, J. W.; Han, S. H.; Weitz, D. A. Direct Observation of Wet Biological Samples by Graphene Liquid Cell Transmission Electron Microscopy. Nano Lett. 2015, 15, 4737-4744. 
14. Wojcik, M.; Hauser, M.; Li, W.; Moon, S.; Xu, K. Graphene-Enabled Electron Microscopy and Correlated Super-Resolution Microscopy of Wet Cells. Nat. Comm. 2015, 6, 7384:7381-7386.

15. Henjes, F.; Bender, C.; von der Heyde, S.; Braun, L.; Mannsperger, H. A.; Schmidt, C.; Wiemann, S.; Hasmann, M.; Aulmann, S.; Beissbarth, T.; Korf, U. Strong Egfr Signaling in Cell Line Models of Erbb2-Amplified Breast Cancer Attenuates Response Towards Erbb2-Targeting Drugs. Oncogenesis 2012, 1, e16.

16. Eigenbrot, C.; Ultsch, M.; Dubnovitsky, A.; Abrahmsen, L.; Hard, T. Structural Basis for High-Affinity Her2 Receptor Binding by an Engineered Protein. Proc. Natl. Acad. Sci. 2010, $107,15039-15044$.

17. Vu, T.; Claret, F. X. Trastuzumab: Updated Mechanisms of Action and Resistance in Breast Cancer. Front Oncol 2012, 2, 62.

18. Zani, B. G.; Edelman, E. R. Cellular Bridges: Routes for Intercellular Communication and Cell Migration. Commun. Integr. Biol. 2010, 3, 215-220.

19. Pasquier, J.; Guerrouahen, B. S.; Al Thawadi, H.; Ghiabi, P.; Maleki, M.; Abu-Kaoud, N.; Jacob, A.; Mirshahi, M.; Galas, L.; Rafii, S.; Le Foll, F.; Rafii, A. Preferential Transfer of Mitochondria from Endothelial to Cancer Cells through Tunneling Nanotubes Modulates Chemoresistance. J. Transl. Med. 2013, 11, 94.

20. Rustom, A.; Saffrich, R.; Markovic, I.; Walther, P.; Gerdes, H. H. Nanotubular Highways for Intercellular Organelle Transport. Science 2004, 303, 1007-1010.

21. Rustom, A. The Missing Link: Does Tunnelling Nanotube-Based Supercellularity Provide a New Understanding of Chronic and Lifestyle Diseases? Open Biol. 2016, 6. 
22. Wang, Y.; Cui, J.; Sun, X.; Zhang, Y. Tunneling-Nanotube Development in Astrocytes Depends on P53 Activation. Cell Death Differ. 2011, 18, 732-742.

23. Peckys, D. B.; de Jonge, N. Studying the Stoichiometry of Epidermal Growth Factor Receptor in Intact Cells Using Correlative Microscopy. J. Vis. Exp. 2015, 103, e53186.

24. Tanaka, K. A.; Suzuki, K. G.; Shirai, Y. M.; Shibutani, S. T.; Miyahara, M. S.; Tsuboi, H.; Yahara, M.; Yoshimura, A.; Mayor, S.; Fujiwara, T. K.; Kusumi, A. Membrane Molecules Mobile Even after Chemical Fixation. Nat. Meth. 2010, 7, 865-866.

25. Arkhipov, A.; Shan, Y. B.; Kim, E. T.; Dror, R. O.; Shaw, D. E. Her2 Activation Mechanism Reflects Evolutionary Preservation of Asymmetric Ectodomain Dimers in the Human Egfr Family. eLife 2013, 2, e00708.

26. Yarden, Y.; Sliwkowski, M. X. Untangling the Erbb Signalling Network. Nat. Rev. Mol. Cell. Biol. 2001, 2, 127-137.

27. Stoyan, D.; Stoyan, H. Estimating Pair Correlation Functions of Planar Cluster Processes. Biom. J. 1996, 38, 259-271.

28. Hoenger, A.; McIntosh, J. R. Probing the Macromolecular Organization of Cells by Electron Tomography. Curr. Opin. Cell Biol. 2009, 21, 89-96.

29. Hermannsdörfer, J.; Tinnemann, V.; Peckys, D. B.; de Jonge, N. The Effect of Electron Beam Irradiation in Environmental Scanning Transmission Electron Microscopy of Whole Cells in Liquid. Microsc. Microanal. 2016, 20, 656-665.

30. Reimer, L.; Kohl, H. Transmission Electron Microscopy: Physics of Image Formation; Springer: New York, 2008. 
31. Lou, E.; Fujisawa, S.; Barlas, A.; Romin, Y.; Manova-Todorova, K.; Moore, M. A.;

Subramanian, S. Tunneling Nanotubes: A New Paradigm for Studying Intercellular

Communication and Therapeutics in Cancer. Commun. Integr. Biol. 2012, 5, 399-403.

32. Pasquier, J.; Galas, L.; Boulange-Lecomte, C.; Rioult, D.; Bultelle, F.; Magal, P.; Webb,

G.; Le Foll, F. Different Modalities of Intercellular Membrane Exchanges Mediate Cell-to-Cell

P-Glycoprotein Transfers in Mcf-7 Breast Cancer Cells. J. Biol. Chem. 2012, 287, 7374-7387.

33. Abounit, S.; Zurzolo, C. Wiring through Tunneling Nanotubes--from Electrical Signals to Organelle Transfer. J. Cell Sci. 2012, 125, 1089-1098.

34. Sun, X.; Wang, Y.; Zhang, J.; Tu, J.; Wang, X. J.; Su, X. D.; Wang, L.; Zhang, Y. Tunneling-Nanotube Direction Determination in Neurons and Astrocytes. Cell Death Dis. 2012, $3, \mathrm{e} 438$.

35. Kimura, S.; Hase, K.; Ohno, H. Tunneling Nanotubes: Emerging View of Their Molecular Components and Formation Mechanisms. Exp. Cell Res. 2012, 318, 1699-1706.

36. Saenz-de-Santa-Maria, I.; Bernardo-Castineira, C.; Enciso, E.; Garcia-Moreno, I.; Chiara, J. L.; Suarez, C.; Chiara, M. D. Control of Long-Distance Cell-to-Cell Communication and Autophagosome Transfer in Squamous Cell Carcinoma Via Tunneling Nanotubes. Oncotarget 2017, 8, 20939-20960.

37. Delage, E.; Cervantes, D. C.; Penard, E.; Schmitt, C.; Syan, S.; Disanza, A.; Scita, G.; Zurzolo, C. Differential Identity of Filopodia and Tunneling Nanotubes Revealed by the Opposite Functions of Actin Regulatory Complexes. Sci. Rep. 2016, 6, 39632.

38. Chung, I.; Reichelt, M.; Shao, L.; Akita, R. W.; Koeppen, H.; Rangell, L.; Schaefer, G.; Mellman, I.; Sliwkowski, M. X. High Cell-Surface Density of Her2 Deforms Cell Membranes. Nat. Comm. 2016, 7, 12742. 
39. Aguilar, Z.; Akita, R. W.; Finn, R. S.; Ramos, B. L.; Pegram, M. D.; Kabbinavar, F. F.; Pietras, R. J.; Pisacane, P.; Sliwkowski, M. X.; Slamon, D. J. Biologic Effects of Heregulin/Neu Differentiation Factor on Normal and Malignant Human Breast and Ovarian Epithelial Cells. Oncogene 1999, 18, 6050-6062.

40. Walker, M. L.; Burgess, S. A.; Sellers, J. R.; Wang, F.; Hammer, J. A., 3rd; Trinick, J.; Knight, P. J. Two-Headed Binding of a Processive Myosin to F-Actin. Nature 2000, 405, 804807.

41. Heath, J. R.; Ribas, A.; Mischel, P. S. Single-Cell Analysis Tools for Drug Discovery and Development. Nat. Rev. Drug. Discov. 2016, 15, 204-216.

42. Valley, C. C.; Lidke, K. A.; Lidke, D. S. The Spatiotemporal Organization of Erbb Receptors: Insights from Microscopy. Cold Spring Harb. Perspect. Biol. 2014, 6.

43. Shivanandan, A.; Deschout, H.; Scarselli, M.; Radenovic, A. Challenges in Quantitative Single Molecule Localization Microscopy. FEBS Lett. 2014, 588, 3595-3602.

44. Sengupta, P.; Jovanovic-Talisman, T.; Skoko, D.; Renz, M.; Veatch, S. L.; LippincottSchwartz, J. Probing Protein Heterogeneity in the Plasma Membrane Using Palm and Pair Correlation Analysis. Nat. Meth. 2011, 8, 969-975.

45. Zhang, R.; Fruhwirth, G. O.; Coban, O.; Barrett, J. E.; Burgoyne, T.; Lee, S. H.; Simonson, P. D.; Baday, M.; Kholodenko, B. N.; Futter, C. E.; Ng, T.; Selvin, P. R. Probing the Heterogeneity of Protein Kinase Activation in Cells by Super-Resolution Microscopy. ACS Nano 2017, 11, 249-257.

46. Ulbrich, M. H.; Isacoff, E. Y. Subunit Counting in Membrane-Bound Proteins. Nat. Meth. 2007, 4, 319-321. 
47. Pierson, J.; Sani, M.; Tomova, C.; Godsave, S.; Peters, P. J. Toward Visualization of Nanomachines in Their Native Cellular Environment. Histochem. Cell Biol. 2009, 132, 253-262.

48. Peckys, D. B.; de Jonge, N. Liquid Scanning Transmission Electron Microscopy:

Imaging Protein Complexes in Their Native Environment in Whole Eukaryotic Cells. Microsc.

Microanal. 2014, 20, 346-365.

49. Bogner, A.; Thollet, G.; Basset, D.; Jouneau, P. H.; Gauthier, C. Wet Stem: A New Development in Environmental Sem for Imaging Nano-Objects Included in a Liquid Phase. Ultramicroscopy 2005, 104, 290-301.

50. Hirano, K.; Kinoshita, T.; Uemura, T.; Motohashi, H.; Watanabe, Y.; Ebihara, T.; Nishiyama, H.; Sato, M.; Suga, M.; Maruyama, Y.; Tsuji, N. M.; Yamamoto, M.; Nishihara, S.; Sato, C. Electron Microscopy of Primary Cell Cultures in Solution and Correlative Optical Microscopy Using Asem. Ultramicroscopy 2014, 143, 52-66.

51. Liv, N.; van Oosten Slingeland, D. S.; Baudoin, J. P.; Kruit, P.; Piston, D. W.; Hoogenboom, J. P. Electron Microscopy of Living Cells During in Situ Fluorescence Microscopy. ACS Nano 2016, 10, 265-273.

52. Hofmann, S.; Braeuninger-Weimer, P.; Weatherup, R. S. Cvd-Enabled Graphene Manufacture and Technology. J. Phys. Chem. Lett. 2015, 6, 2714-2721.

53. Weatherup, R. S.; Shahani, A. J.; Wang, Z. J.; Mingard, K.; Pollard, A. J.; Willinger, M. G.; Schloegl, R.; Voorhees, P. W.; Hofmann, S. In Situ Graphene Growth Dynamics on Polycrystalline Catalyst Foils. Nano Lett. 2016.

54. Braeuninger-Weimer, P.; Brennan, B.; Pollard, A. J.; Hofmann, S. Understanding and Controlling Cu-Catalyzed Graphene Nucleation: The Role of Impurities, Roughness, and Oxygen Scavenging. Chem. Mater. 2016, 28, 8905-8915. 
55. Verch, A.; Pfaff, M.; De Jonge, N. Exceptionally Slow Movement of Gold Nanoparticles at a Solid:Liquid Interface Investigated by Scanning Transmission Electron Microscopy.

Langmuir 2015, 31, 6956-6964.

56. de Jonge, N.; Bigelow, W. C.; Veith, G. M. Atmospheric Pressure Scanning Transmission Electron Microscopy. Nano Lett. 2010, 10, 1028-1031.

57. Joy, D. C.; Joy, C. S. Scanning Electron Microscope Imaging in Liquids - Some Data on Electron Interactions in Water. J. Micr. 2005, 221, 84-99.

58. de Jonge, N.; Poirier-Demers, N.; Demers, H.; Peckys, D. B.; Drouin, D. NanometerResolution Electron Microscopy through Micrometers-Thick Water Layers. Ultramicroscopy 2010, 110, 1114-1119. 

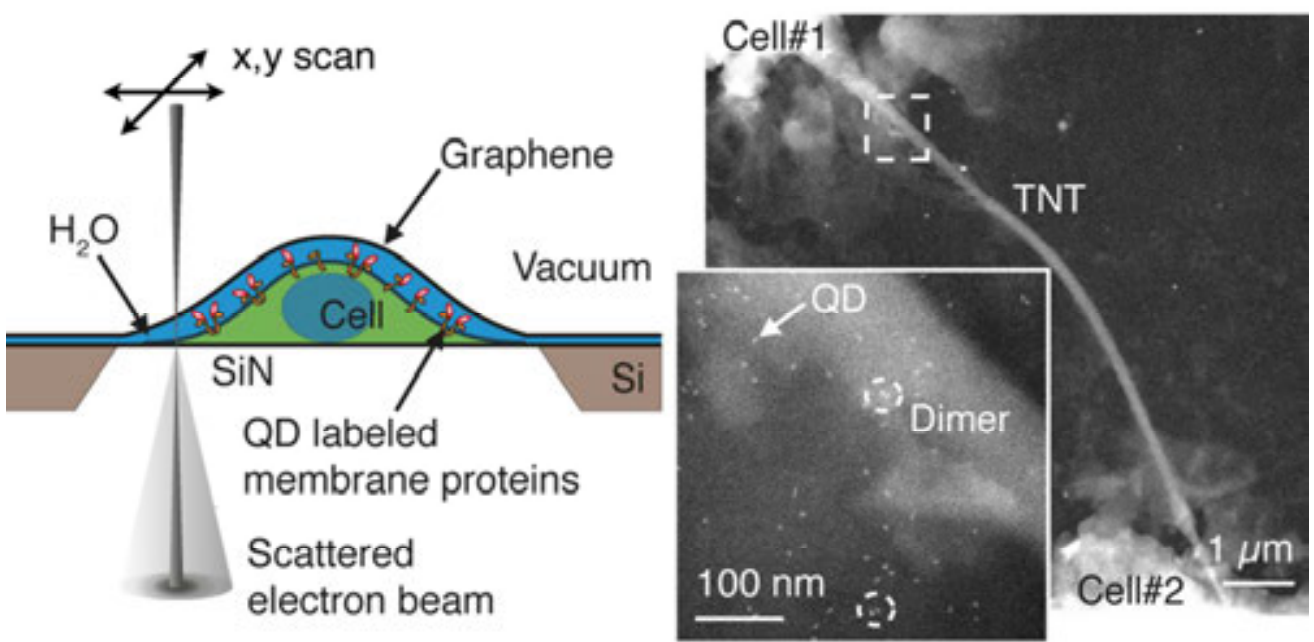

TOC graphic

$82 \times 44 \mathrm{~mm}(300 \times 300$ DPI $)$ 


\section{Cultivation of cells on microchip}

\section{Page 39 of $\mathbf{4 2}$}

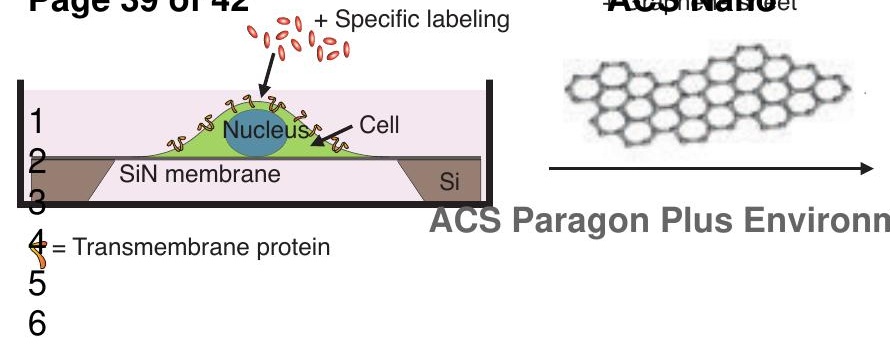

Examination with STEM

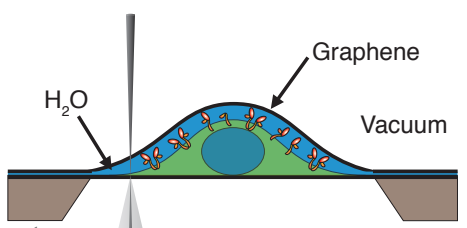




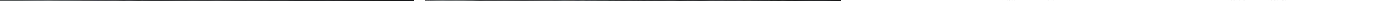


